Review

\title{
Long Non-Coding RNAs in Cancer and Development: Where Do We Go from Here?
}

\section{Monika Haemmerle ${ }^{1,2}$ and Tony Gutschner ${ }^{3, *}$}

1 Department of Gynecologic Oncology and Reproductive Medicine, the University of Texas MD Anderson Cancer Center, Houston, TX 77054, USA; E-Mail: mhaemmerle@mdanderson.org

2 Institute of Pathology, University Hospital Heidelberg, Heidelberg 69120, Germany

3 Department of Genomic Medicine, the University of Texas MD Anderson Cancer Center, Houston, TX 77054, USA

* Author to whom correspondence should be addressed; E-Mail: tgutschner@mdanderson.org; Tel.: +1-713-792-8628; Fax: +1-713-792-6882.

Academic Editor: Martin Pichler

Received: 16 December 2014 / Accepted: 30 December 2014 / Published: 8 January 2015

\begin{abstract}
Recent genome-wide expression profiling studies have uncovered a huge amount of novel, long non-protein-coding RNA transcripts (lncRNA). In general, these transcripts possess a low, but tissue-specific expression, and their nucleotide sequences are often poorly conserved. However, several studies showed that lncRNAs can have important roles for normal tissue development and regulate cellular pluripotency as well as differentiation. Moreover, IncRNAs are implicated in the control of multiple molecular pathways leading to gene expression changes and thus, ultimately modulate cell proliferation, migration and apoptosis. Consequently, deregulation of lncRNA expression contributes to carcinogenesis and is associated with human diseases, e.g., neurodegenerative disorders like Alzheimer's Disease. Here, we will focus on some major challenges of lncRNA research, especially loss-of-function studies. We will delineate strategies for lncRNA gene targeting in vivo, and we will briefly discuss important consideration and pitfalls when investigating lncRNA functions in knockout animal models. Finally, we will highlight future opportunities for lncRNAs research by applying the concept of cross-species comparison, which might contribute to novel disease biomarker discovery and might identify lncRNAs as potential therapeutic targets.
\end{abstract}


Keywords: functional genomics; genetically engineered mouse models (GEMM); long intergenic RNA (lincRNA); metastasis; metastasis-associated lung adenocarcinoma transcript 1 (MALAT1); HOX transcript antisense RNA (HOTAIR)

\section{The Emergence of IncRNA}

For more than five decades it has been known that DNA sequences are transcribed into RNA but never get translated into protein. This challenged the central dogma of molecular biology that put RNA as a simple messenger between the DNA and protein worlds. However, most researchers ignored these untranslated RNAs, assuming that they do not serve a useful purpose. In the mid-1990s, researchers like John Mattick started to argue that these RNAs transmit regulatory information, which might be associated with the emergence of multicellular organisms [1]. Only recently has this idea received strong support by the observation that the proportion of non-coding genomic sequences correlates broadly with the developmental complexity [2]. While this finding is still controversial and might be explained by an inefficient selection against non-functional genomic elements as body size increases and population size decreases [3], progress in the field of genome-wide sequencing technology and transcriptome analysis led to the astonishing notion that up to $70 \%-90 \%$ of the human genome is transcribed into RNA [4-6]. However, only $1 \%-2 \%$ of the human genome contains the blueprint for protein-coding transcripts, which led to the birth of a new category of transcripts-long non-coding RNAs (lncRNAs). Many of these lncRNAs are expressed in a tissue-specific and timely restricted manner and show a low level of expression and sequence conservation [7-9]. While "transcription" per se does not automatically equal "function", research over the last decade has shown that lncRNAs can have important functions in developmental processes, influence differentiation, and play a role in human diseases, e.g., cancer [10] or neurodegenerative disorders like Alzheimer's Disease [11,12]. Particularly interesting is the notion that about $95 \%$ of all variants associated with complex human diseases map to non-coding, presumably regulatory, sequences [13,14]. However, lncRNA research is still in its infancy and scientists are only beginning to unravel the molecular functions of these new transcripts. As in any other developing area, novel tools and model systems need to be developed first to allow in-depth understanding of molecular details. Bona fide animal models, i.e., transgenic overexpression or knockout animals are the gold standard for functional genomics and are routinely used to analyze the function of protein-coding genes. However, recent genetic knockout experiments in mice have uncovered pitfalls that have to be considered, if the gene of interest is a non-coding RNA.

In this review, we will discuss the challenges associated with probing the in vivo function of lncRNAs in animal models. Moreover, we will highlight the power of cross-species comparisons and how this approach might be used to identify conserved lncRNAs with a role in human diseases, e.g., cancer.

\section{LncRNA Knockout-One Aim, Multiple Options}

Several targeting strategies can be used for knocking out protein-coding genes: exon replacements, in frame stop-codon insertion or introduction of insertions that lead to a frame shift, as well as whole gene excisions, truncations or (point) mutations of functional domains. Most of these manipulations need active 
translation of the RNA transcript to achieve the disruptive effect, and thus are not feasible for lncRNAs. Hence, lncRNA targeting strategies must prevent the whole transcript from being made (Figure 1).

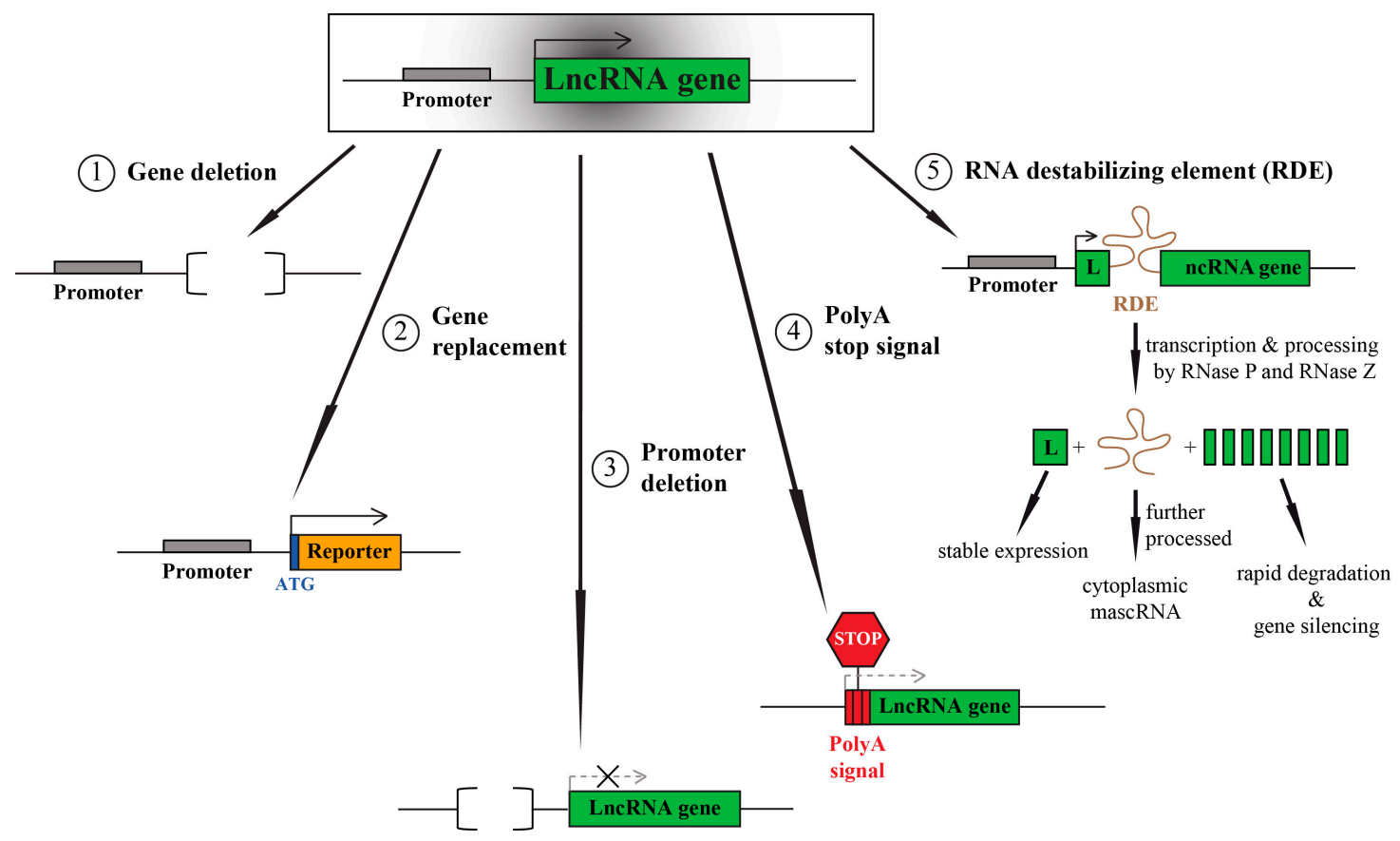

Figure 1. Long non-protein-coding RNA (LncRNA) targeting strategies for in vivo loss-of-function studies.

The easiest way to achieve this requires the deletion of the complete gene sequence which relies on homologous recombination, and can be used to generate constitutive or conditional knockout animals. We and our colleagues applied this strategy to generate constitutive Malat1 knockout mice [15].

A related strategy replaces the lncRNA sequence with a reporter gene (monoallelic or biallelic), e.g., LacZ. If the endogenous lncRNA promoter is kept intact during the replacement, it can drive reporter gene expression thereby revealing lncRNA expression patterns in vivo. This strategy has been applied by John Rinn, Paolo Arlotta and co-workers in an impressive large-scale knockout project to investigate the phenotypes of 18 lncRNA knockouts in mice [16].

Instead of deleting or replacing the whole lncRNA it is also possible to just remove the endogenous promoter. The deletion can be small (only a few hundred base pairs) and might only minimally perturb the genomic locus (in contrast to the deletion of the complete gene). However, many protein-coding and non-coding genes have alternative promoters and hence will retain expression of one or more isoforms, if only one promoter is targeted. Moreover, divergent transcription of lncRNAs in close proximity to protein-coding genes is frequently observed [17-19]. In such a scenario promoter deletions may affect both genes and make interpretation of results more complicated. Promoter targeting strategies were used to target the neighboring lncRNAs Neat1 and Malat1 [20,21].

A third strategy for targeting lncRNAs is the integration of strong transcriptional stop signals at the very 5 '-end of the non-coding transcript. The integration of polyadenylation (poly A) signals at the beginning of the transcript causes premature cleavage and polyadenylation of the lncRNA, and finally its degradation. This approach can yield strong, but also incomplete lncRNA depletion, depending on the lncRNA abundance. We successfully applied this strategy, in combination with integration of a 
selection marker (Green Fluorescent Protein, GFP) to silence the lncRNA Malat1 in human cancer cells [22,23]. Other lncRNAs targeted by this approach include, e.g., Airn and Evf2, and this approach was chosen to generate a third Malat1 knockout mouse model [24-26].

An additional and novel strategy could be the use of RNA destabilizing elements. In our previous study, we identified an efficient RNA destabilizing element derived from the 3'-end of the endogenous Malat 1 transcript [22]. This motif is recognized and processed by nuclear RNase P, which cuts at the 5 '-end of the motif, and ultimately leads to the degradation of the downstream 3'-end of the RNA. In contrast, the upstream 5 '-end of the transcript is stabilized due to the formation of a triple helical structure [27-30]. If inserted after the open reading frame of a reporter gene, this element also enables efficient protein translation (own data and [30]). The recognition of this motif by RNase $\mathrm{P}$ depends on its orientation and therefore should allow strand-specific silencing [22]. This is important, if the lncRNA is antisense to a protein-coding gene. Furthermore, Cre-mediated inversion of its orientation would enable a timely controlled gene silencing. In analogy to the polyA stop signal, integration of this Malat1-derived element at the beginning of a transcript would cause a cleavage and silencing of the downstream sequences. Importantly, this does not depend on RNA polymerase II and its associated factors, and thus represents an interesting strategy to target not only RNA polymerase II, but also I and III transcripts. However, to our knowledge this idea has not been tested so far in vivo. One thing that needs to be considered is the generation of a small ncRNA (mascRNA) during the cleavage and processing events. The tRNA-like mascRNA will be exported to the cytoplasm where it might have a so far unknown function [29].

\section{LncRNA Knockouts-Things to Consider}

The aforementioned strategies represent solutions to the problem of "How to target lcnRNAs?", but they immediately raise another question: Which strategy is the "right" one? Unfortunately, there is no "one fits all" answer to this question. To make a good decision requires some prior knowledge about the lncRNA, its genomic and cellular localization, and its putative function. For example, many lncRNAs act as primary host gene for classes of small non-coding RNAs, e.g., microRNAs. Thus, deletion of the complete lncRNA locus will disrupt the function of multiple transcripts in parallel. Moreover, lncRNAs might regulate the expression of neighboring genes in cis, or of distant genes in trans. The lncRNA might achieve this via physical interaction with proteins or other nucleic acids. Hence, the RNA product is important and blocking its production via insertion of stop signals or other destabilizing elements (at the beginning of the transcript) might be the strategy of choice. Alternatively, the simple act of transcription through an lncRNA gene locus could be critical because of the induction of chromatin changes and/or modifications, or the recruitment of other proteins, e.g., transcription factors. In this case, the RNA transcript is only a by-product and modulation of the transcription event, e.g., by targeting the promoter, might be an appropriate strategy.

Consequently, multiple strategies might be considered and even used in parallel to help interpretation of phenotypic results. Minimal genomic disruptions should be used and control manipulations should be performed to distinguish between effects caused by the intended disruption of the lncRNA or the unintended disruption of neighboring genes or regulatory DNA elements with which lncRNA loci are interleaved across the entire genome. In the case of trans-acting lncRNAs, phenotypes should be 
rescued upon expression of the lncRNA from an independent transgene. The transgene should contain the endogenous regulatory sequences to maintain physiologically relevant lncRNA expression levels. Moreover, correct developmental timing as well as tissue- and cell-specific lncRNA expression patterns should be considered in these rescue experiments. Given the large size of some lncRNAs (up to several hundred $\mathrm{kb}$ ) these experiments might be very challenging. In cases where lncRNAs act in cis, a combination of several targeting strategies might be required to unravel true lncRNA-dependent effects. For an in-depth description and detailed discussion about the advantages and challenges associated with current lncRNA knockout strategies the reader is referred to Bassett et al. [31].

\section{LncRNAs in Development_-Lack of Phenotypes besides High Conservation}

Only a few lncRNA knockout studies have been conducted till today. Our own knockout study, together with the work of two other groups, targeting the lncRNA Malatl led to the finding that the loss of this lncRNA is compatible with life and development [15,21,25]. This finding was highly unexpected given the strong nucleotide sequence conservation in mammals, and the ubiquitous and abundant expression of Malat1. Moreover, MALAT1 has been linked to several human cancers and was shown to regulate cell cycle progression, apoptosis, migration and metastasis of cancer cells [32,33]. On the molecular level MALAT1 was shown to regulate alternative splicing of specific transcripts as well as the expression level of different genes, presumably via its interaction with chromatin modulators [33-37]. The lack of an overt phenotype under physiological conditions of the three published Malat1 knockout mouse models that had been generated by different targeting strategies might be explained by functional redundancy or compensatory mechanisms. In the future, application of certain stresses or other pathological scenarios might help to reveal a phenotype. In this line, a recent study could show that MALAT1 expression in endothelial cells is up-regulated under hypoxia and controls the phenotypic switch from migration to proliferation in endothelial cells in vitro and in vivo [38].

The example of Malat1 is not the only case where the knockout model did not yield a discernable phenotype. Other knockout studies targeting broadly expressed lncRNAs (e.g., Neatl) or highly conserved regions of the mammalian genome did not result in developmental aberrations [20,39]. Remarkably, deletion of 13 out of 18 carefully selected lncRNA genes that were targeted by Sauvageau, Goff, Lodata et al. did not reveal a phenotype [16]. Altogether, these surprising findings might be explained by functional redundancies and compensatory mechanisms that might develop in constitutive knockout models, and the acute depletion of the lncRNA gene in conditional model systems might yield different outcomes. Moreover, many lncRNAs are primate-specific and a large fraction is expressed in the brain [8,40]. This suggests that much of the lncRNA-mediated genetic information is devoted to brain function. Therefore, besides histopathological examination of the animals' organs and tissues, phenotypic analyses need to consider tissue-/cell-type specific lncRNA expression pattern, and need to include cognitive screens and a careful observation of the animals' behavior.

\section{LncRNAs in Cancer-Cross-Species Comparisons to Reveal Cancer Genes and Functions}

Many lncRNAs are differentially expressed between normal and malignant cells, and initial in vitro experiments revealed a function of these lncRNAs in controlling cell cycle progression, apoptosis or 
migration. Malat1 was one of the first lncRNA linked to human cancer [41]. Given Malatl's well-established role in a broad range of human cancer cells and its newly identified role in the tumor microenvironment, i.e., in endothelial cells, raises the exciting question: Will Malat1 deletion impair tumor growth and progression in genetically engineered mouse models (GEMMs)? A straightforward way to answer this question is to cross the Malat $^{-/-}$mouse with several of the relevant tumor models that show spontaneous metastasis, e.g., the RIP-Tag model of pancreatic islet carcinoma [42], the MMTV-PyMT, MMTV-Erbb2 and other models of breast cancer [43], or one of the KRAS-driven lung cancer models [44]. For a more detailed analysis, conditional Malat1 knockout models would be needed to delete this lncRNA at a certain stage during the tumor development, or in a specific compartment of the tumor environment (endothelial cells vs. epithelial tumor cells). Alternatively, non-germline genetically engineered mouse models could be used as well offering flexibility, speed and uniformity at reduced costs [45].

These experimental strategies might be exploited for other de-regulated lncRNAs as well and are not limited to Malat1. For example, the expression of the lncRNA Hotair (HOX transcript antisense RNA) is increased in primary breast tumors and metastases, and its expression level in primary tumors is a predictor of eventual metastasis and survival [46]. Hotair ${ }^{--}$mice are viable [47], and thus would enable functional and therapeutic studies in murine tumor models.

An alternative yet complementary approach to investigate the role of lncRNAs in cancer could take advantage of existing murine tumor models to analyze structural and sequence alterations (gene fusions, copy-number alterations, mutations), and to profile the expression of conserved lncRNAs during cancer progression. The obtained data could be integrated with data from human cancer patients to pinpoint recurrent and conserved genetic alterations that involve putative oncogenic or tumorsuppressive lncRNAs. These analyses could be extended to investigate mechanisms of therapy resistance that might be mediated by lncRNAs. However, the biggest challenge is the identification of conserved lncRNAs. In general, gene conservation is judged based on sequence similarities - either on the level of nucleotide or amino acid sequence. While this is useful for protein-coding genes it is not directly applicable for lncRNAs due to their less conserved nucleotide sequences [48,49]. For example, a comparison between lncRNAs expressed in mammals and zebrafish identified only a few significantly conserved sequences, mostly restricted to short sequence stretches [50]. Hence, lncRNAs evolve rapidly and often lack orthologs in other species. Therefore, additional dimensions of conservation need to be considered when working with non-coding RNAs [51].

Cross-species cancer gene analysis, which integrates multidimensional genome-wide cancer data sets from human and mice, represents a powerful approach for identifying and validating cancer-relevant genes [52,53]. Application of this concept to the field of lncRNAs has the potential to identify novel therapeutic targets and putative biomarkers.

\section{Conclusions and Outlook}

LncRNAs are more and more recognized as important regulators of diverse cellular processes and are actively involved in signaling pathways [54]. Leveraging the power of genome-wide sequencing techniques will generate a comprehensive catalogue of lncRNAs involved in human diseases, e.g., cancer. The development of novel assays to map lncRNA interactions with proteins and other nucleic 
acids will help to further investigate the molecular function of lncRNAs [34,55-57]. Novel assays might also be developed to study the interaction between lncRNAs and additional biomolecules, e.g., lipids or small second messengers (e.g., phosphatidylinositol-(3,4,5)-trisphosphate). Further insights into lncRNA conservation might come from newly developed genome-scale structure mapping techniques [58-61]. Integration of structural information and lncRNA interaction sites will guide future lncRNA targeting strategies. The use of novel genome editing tools, i.e., the CRISPR/Cas9 system [62] will largely contribute to generate better in vivo and in vitro models for basic lncRNA research. Translational research efforts might benefit from these newly developed mouse models by integrating lncRNAs into disease modeling, and will generate valuable tools for preclinical testing of anti-lncRNA therapeutics. Effective therapeutics might target the lncRNA directly via small interfering RNA (siRNA) or antisense oligonucleotide (ASO) mediated silencing. Alternatively, lncRNA function might be inhibited indirectly via blocking the physical association with its interaction partners. Recent progress in the field of RNAi therapeutics will help to deliver these anti-lncRNA therapeutics in vivo [63,64].

\section{Acknowledgments}

The authors apologize to all scientists whose important work could not be cited in this review due to space constraints. We wish to thank our colleagues from Heidelberg, Frankfurt and Bad Nauheim who were involved in generating and characterizing the Malat1 knockout mice. Monika Haemmerle's work in the lab of Anil Sood is supported by a Research Fellowship of the Deutsche Forschungsgemeinschaft (DFG). Tony Gutschner is an Odyssey Postdoctoral Fellow and his work in the lab of Lynda Chin is supported in part by the Odyssey Program at The University of Texas MD Anderson Cancer Center.

\section{Author Contributions}

Tony Gutschner conceptualized this review; and Monika Haemmerle and Tony Gutschner prepared the figure and wrote the manuscript.

\section{Conflicts of Interest}

The authors declare no conflict of interest.

\section{References}

1. Mattick, J.S. Introns: Evolution and function. Curr. Opin. Genet. Dev. 1994, 4, 823-831.

2. Liu, G.; Mattick, J.S.; Taft, R.J. A meta-analysis of the genomic and transcriptomic composition of complex life. Cell Cycle 2013, 12, 2061-2072.

3. Lynch, M.; Walsh, B. The Origins of Genome Architecture; Sinauer Associates, Inc.: Sunderland, MA, USA, 2007.

4. Carninci, P.; Kasukawa, T.; Katayama, S.; Gough, J.; Frith, M.C.; Maeda, N.; Oyama, R.; Ravasi, T.; Lenhard, B.; Wells, C.; et al. The transcriptional landscape of the mammalian genome. Science 2005, 309, 1559-1563. 
5. Cheng, J.; Kapranov, P.; Drenkow, J.; Dike, S.; Brubaker, S.; Patel, S.; Long, J.; Stern, D.; Tammana, H.; Helt, G.; et al. Transcriptional maps of 10 human chromosomes at 5-nucleotide resolution. Science 2005, 308, 1149-1154.

6. Consortium, E.P.; Birney, E.; Stamatoyannopoulos, J.A.; Dutta, A.; Guigo, R.; Gingeras, T.R.; Margulies, E.H.; Weng, Z.; Snyder, M.; Dermitzakis, E.T.; et al. Identification and analysis of functional elements in $1 \%$ of the human genome by the encode pilot project. Nature 2007, 447, 799-816.

7. Cabili, M.N.; Trapnell, C.; Goff, L.; Koziol, M.; Tazon-Vega, B.; Regev, A.; Rinn, J.L. Integrative annotation of human large intergenic non-coding RNAs reveals global properties and specific subclasses. Genes Dev. 2011, 25, 1915-1927.

8. Derrien, T.; Johnson, R.; Bussotti, G.; Tanzer, A.; Djebali, S.; Tilgner, H.; Guernec, G.; Martin, D.; Merkel, A.; Knowles, D.G.; et al. The GENCODE v7 catalog of human long non-coding RNAs: Analysis of their gene structure, evolution, and expression. Genome Res. 2012, 22, 1775-1789.

9. Dinger, M.E.; Amaral, P.P.; Mercer, T.R.; Pang, K.C.; Bruce, S.J.; Gardiner, B.B.; Askarian-Amiri, M.E.; Ru, K.; Solda, G.; Simons, C.; et al. Long non-coding RNAs in mouse embryonic stem cell pluripotency and differentiation. Genome Res. 2008, 18, 1433-1445.

10. Gutschner, T.; Diederichs, S. The hallmarks of cancer: A long non-coding RNA point of view. RNA Biol. 2012, 9, 703-719.

11. Faghihi, M.A.; Modarresi, F.; Khalil, A.M.; Wood, D.E.; Sahagan, B.G.; Morgan, T.E.; Finch, C.E.; St-Laurent, G., III; Kenny, P.J.; Wahlestedt, C. Expression of a non-coding RNA is elevated in Alzheimer's Disease and drives rapid feed-forward regulation of $\beta$-secretase. Nat. Med. 2008, 14, 723-730.

12. Pastori, C.; Wahlestedt, C. Involvement of long non-coding RNAs in diseases affecting the central nervous system. RNA Biol. 2012, 9, 860-870.

13. Cheetham, S.W.; Gruhl, F.; Mattick, J.S.; Dinger, M.E. Long non-coding RNAs and the genetics of cancer. Br. J. Cancer 2013, 108, 2419-2425.

14. Freedman, M.L.; Monteiro, A.N.; Gayther, S.A.; Coetzee, G.A.; Risch, A.; Plass, C.; Casey, G.; de Biasi, M.; Carlson, C.; Duggan, D.; et al. Principles for the post-GWAS functional characterization of cancer risk loci. Nat. Genet. 2011, 43, 513-518.

15. Eissmann, M.; Gutschner, T.; Hammerle, M.; Gunther, S.; Caudron-Herger, M.; Gross, M.; Schirmacher, P.; Rippe, K.; Braun, T.; Zornig, M.; et al. Loss of the abundant nuclear non-coding RNA Malat1 is compatible with life and development. RNA Biol. 2012, 9, 1076-1087.

16. Sauvageau, M.; Goff, L.A.; Lodato, S.; Bonev, B.; Groff, A.F.; Gerhardinger, C.; Sanchez-Gomez, D.B.; Hacisuleyman, E.; Li, E.; Spence, M.; et al. Multiple knockout mouse models reveal lincRNAs are required for life and brain development. eLIFE 2013, 2, e01749.

17. Hung, T.; Wang, Y.; Lin, M.F.; Koegel, A.K.; Kotake, Y.; Grant, G.D.; Horlings, H.M.; Shah, N.; Umbricht, C.; Wang, P.; et al. Extensive and coordinated transcription of non-coding RNAs within cell-cycle promoters. Nat. Genet. 2011, 43, 621-629.

18. Ponjavic, J.; Oliver, P.L.; Lunter, G.; Ponting, C.P. Genomic and transcriptional co-localization of protein-coding and long non-coding RNA pairs in the developing brain. PLoS Genet. 2009, 5 , e1000617. 
19. Sigova, A.A.; Mullen, A.C.; Molinie, B.; Gupta, S.; Orlando, D.A.; Guenther, M.G.; Almada, A.E.; Lin, C.; Sharp, P.A.; Giallourakis, C.C.; et al. Divergent transcription of long non-coding RNA/mRNA gene pairs in embryonic stem cells. Proc. Natl. Acad. Sci. USA 2013, 110, 2876-2881.

20. Nakagawa, S.; Naganuma, T.; Shioi, G.; Hirose, T. Paraspeckles are subpopulation-specific nuclear bodies that are not essential in mice. J. Cell Biol. 2011, 193, 31-39.

21. Zhang, B.; Arun, G.; Mao, Y.S.; Lazar, Z.; Hung, G.; Bhattacharjee, G.; Xiao, X.; Booth, C.J.; $\mathrm{Wu}$, J.; Zhang, C.; et al. The lncRNA Malat1 is dispensable for mouse development but its transcription plays a cis-regulatory role in the adult. Cell Rep. 2012, 2, 111-123.

22. Gutschner, T.; Baas, M.; Diederichs, S. Non-coding RNA gene silencing through genomic integration of RNA destabilizing elements using zinc finger nucleases. Genome Res. 2011, 21, 1944-1954.

23. Gutschner, T. Silencing long noncoding RNAs with genome-editing tools. Methods Mol. Biol. 2015, 1239, 241-250.

24. Bond, A.M.; Vangompel, M.J.; Sametsky, E.A.; Clark, M.F.; Savage, J.C.; Disterhoft, J.F.; Kohtz, J.D. Balanced gene regulation by an embryonic brain ncRNA is critical for adult hippocampal gaba circuitry. Nat. Neurosci. 2009, 12, 1020-1027.

25. Nakagawa, S.; Ip, J.Y.; Shioi, G.; Tripathi, V.; Zong, X.; Hirose, T.; Prasanth, K.V. Malat1 is not an essential component of nuclear speckles in mice. RNA 2012, 18, 1487-1499.

26. Sleutels, F.; Zwart, R.; Barlow, D.P. The non-coding air RNA is required for silencing autosomal imprinted genes. Nature 2002, 415, 810-813.

27. Brown, J.A.; Bulkley, D.; Wang, J.; Valenstein, M.L.; Yario, T.A.; Steitz, T.A.; Steitz, J.A. Structural insights into the stabilization of malat1 noncoding RNA by a bipartite triple helix. Nat. Struct. Mol. Biol. 2014, 21, 633-640.

28. Peart, N.; Sataluri, A.; Baillat, D.; Wagner, E.J. Non-mRNA 3' end formation: How the other half lives. Wiley Interdiscip. Rev. RNA 2013, 4, 491-506.

29. Wilusz, J.E.; Freier, S.M.; Spector, D.L. 3' End processing of a long nuclear-retained noncoding RNA yields a tRNA-like cytoplasmic RNA. Cell 2008, 135, 919-932.

30. Wilusz, J.E.; JnBaptiste, C.K.; Lu, L.Y.; Kuhn, C.D.; Joshua-Tor, L.; Sharp, P.A. A triple helix stabilizes the $3^{\prime}$ ends of long noncoding RNAs that lack poly (A) tails. Genes Dev. 2012, 26, 2392-2407.

31. Bassett, A.R.; Akhtar, A.; Barlow, D.P.; Bird, A.P.; Brockdorff, N.; Duboule, D.; Ephrussi, A.; Ferguson-Smith, A.C.; Gingeras, T.R.; Haerty, W.; et al. Considerations when investigating lncRNA function in vivo. eLife 2014, 3, e03058.

32. Gutschner, T.; Hammerle, M.; Diederichs, S. MALAT1-A paradigm for long noncoding RNA function in cancer. J. Mol. Med. 2013, 91, 791-801.

33. Gutschner, T.; Hammerle, M.; Eissmann, M.; Hsu, J.; Kim, Y.; Hung, G.; Revenko, A.; Arun, G.; Stentrup, M.; Gross, M.; et al. The non-coding RNA malat1 is a critical regulator of the metastasis phenotype of lung cancer cells. Cancer Res. 2013, 73, 1180-1189.

34. Engreitz, J.M.; Sirokman, K.; McDonel, P.; Shishkin, A.A.; Surka, C.; Russell, P.; Grossman, S.R.; Chow, A.Y.; Guttman, M.; Lander, E.S. RNA-RNA interactions enable specific targeting of non-coding RNAs to nascent pre-mRNAs and chromatin sites. Cell 2014, 159, 188-199. 
35. Tripathi, V.; Ellis, J.D.; Shen, Z.; Song, D.Y.; Pan, Q.; Watt, A.T.; Freier, S.M.; Bennett, C.F.; Sharma, A.; Bubulya, P.A.; et al. The nuclear-retained non-coding RNA Malat1 regulates alternative splicing by modulating SR splicing factor phosphorylation. Mol. Cell 2010, 39, 925-938.

36. West, J.A.; Davis, C.P.; Sunwoo, H.; Simon, M.D.; Sadreyev, R.I.; Wang, P.I.; Tolstorukov, M.Y.; Kingston, R.E. The long noncoding RNAs Neat1 and Malat1 bind active chromatin sites. Mol. Cell 2014, 55, 791-802.

37. Yang, L.; Lin, C.; Liu, W.; Zhang, J.; Ohgi, K.A.; Grinstein, J.D.; Dorrestein, P.C.; Rosenfeld, M.G. ncRNA- and Pc2 methylation-dependent gene relocation between nuclear structures mediates gene activation programs. Cell 2011, 147, 773-788.

38. Michalik, K.M.; You, X.; Manavski, Y.; Doddaballapur, A.; Zornig, M.; Braun, T.; John, D.; Ponomareva, Y.; Chen, W.; Uchida, S.; et al. Long non-coding RNA Malat1 regulates endothelial cell function and vessel growth. Circ. Res. 2014, 114, 1389-1397.

39. Ahituv, N.; Zhu, Y.; Visel, A.; Holt, A.; Afzal, V.; Pennacchio, L.A.; Rubin, E.M. Deletion of ultraconserved elements yields viable mice. PLoS Biol. 2007, 5, e234.

40. Mercer, T.R.; Dinger, M.E.; Sunkin, S.M.; Mehler, M.F.; Mattick, J.S. Specific expression of long non-coding RNAs in the mouse brain. Proc. Natl. Acad. Sci. USA 2008, 105, 716-721.

41. Ji, P.; Diederichs, S.; Wang, W.; Boing, S.; Metzger, R.; Schneider, P.M.; Tidow, N.; Brandt, B.; Buerger, H.; Bulk, E.; et al. Malat-1, a novel noncoding RNA, and thymosin $\beta 4$ predict metastasis and survival in early-stage non-small cell lung cancer. Oncogene 2003, 22, 8031-8041.

42. Paez-Ribes, M.; Allen, E.; Hudock, J.; Takeda, T.; Okuyama, H.; Vinals, F.; Inoue, M.; Bergers, G.; Hanahan, D.; Casanovas, O. Antiangiogenic therapy elicits malignant progression of tumors to increased local invasion and distant metastasis. Cancer Cell 2009, 15, 220-231.

43. Kim, I.S.; Baek, S.H. Mouse models for breast cancer metastasis. Biochem. Biophys. Res. Commun. 2010, 394, 443-447.

44. Kwon, M.C.; Berns, A. Mouse models for lung cancer. Mol. Oncol. 2013, 7, 165-177.

45. Heyer, J.; Kwong, L.N.; Lowe, S.W.; Chin, L. Non-germline genetically engineered mouse models for translational cancer research. Nat. Rev. Cancer 2010, 10, 470-480.

46. Gupta, R.A.; Shah, N.; Wang, K.C.; Kim, J.; Horlings, H.M.; Wong, D.J.; Tsai, M.C.; Hung, T.; Argani, P.; Rinn, J.L.; et al. Long non-coding RNA HOTAIR reprograms chromatin state to promote cancer metastasis. Nature 2010, 464, 1071-1076.

47. Li, L.; Liu, B.; Wapinski, O.L.; Tsai, M.C.; Qu, K.; Zhang, J.; Carlson, J.C.; Lin, M.; Fang, F.; Gupta, R.A.; et al. Targeted disruption of HOTAIR leads to homeotic transformation and gene derepression. Cell Rep. 2013, 5, 3-12.

48. Guttman, M.; Amit, I.; Garber, M.; French, C.; Lin, M.F.; Feldser, D.; Huarte, M.; Zuk, O.; Carey, B.W.; Cassady, J.P.; et al. Chromatin signature reveals over a thousand highly conserved large non-coding RNAs in mammals. Nature 2009, 458, 223-227.

49. Ponjavic, J.; Ponting, C.P.; Lunter, G. Functionality or transcriptional noise? Evidence for selection within long non-coding RNAs. Genome Res. 2007, 17, 556-565.

50. Ulitsky, I.; Shkumatava, A.; Jan, C.H.; Sive, H.; Bartel, D.P. Conserved function of lincRNAs in vertebrate embryonic development despite rapid sequence evolution. Cell 2011, 147, 1537-1550.

51. Diederichs, S. The four dimensions of noncoding RNA conservation. Trends Genet. 2014, 30, 121-123. 
52. Kim, M.; Gans, J.D.; Nogueira, C.; Wang, A.; Paik, J.H.; Feng, B.; Brennan, C.; Hahn, W.C.; Cordon-Cardo, C.; Wagner, S.N.; et al. Comparative oncogenomics identifies NEDD9 as a melanoma metastasis gene. Cell 2006, 125, 1269-1281.

53. Zender, L.; Spector, M.S.; Xue, W.; Flemming, P.; Cordon-Cardo, C.; Silke, J.; Fan, S.T.; Luk, J.M.; Wigler, M.; Hannon, G.J.; et al. Identification and validation of oncogenes in liver cancer using an integrative oncogenomic approach. Cell 2006, 125, 1253-1267.

54. Xing, Z.; Lin, A.; Li, C.; Liang, K.; Wang, S.; Liu, Y.; Park, P.K.; Qin, L.; Wei, Y.; Hawke, D.H.; et al. lncRNA directs cooperative epigenetic regulation downstream of chemokine signals. Cell 2014, $159,1110-1125$.

55. Engreitz, J.M.; Pandya-Jones, A.; McDonel, P.; Shishkin, A.; Sirokman, K.; Surka, C.; Kadri, S.; Xing, J.; Goren, A.; Lander, E.S.; et al. The Xist lncRNA exploits three-dimensional genome architecture to spread across the X chromosome. Science 2013, 341, 6147.

56. Buenrostro, J.D.; Araya, C.L.; Chircus, L.M.; Layton, C.J.; Chang, H.Y.; Snyder, M.P.; Greenleaf, W.J. Quantitative analysis of RNA-protein interactions on a massively parallel array reveals biophysical and evolutionary landscapes. Nat. Biotechnol. 2014, 32, 562-568.

57. Quinn, J.J.; Ilik, I.A.; Qu, K.; Georgiev, P.; Chu, C.; Akhtar, A.; Chang, H.Y. Revealing long non-coding RNA architecture and functions using domain-specific chromatin isolation by RNA purification. Nat. Biotechnol. 2014, 32, 933-940.

58. Ding, Y.; Tang, Y.; Kwok, C.K.; Zhang, Y.; Bevilacqua, P.C.; Assmann, S.M. In vivo genome-wide profiling of RNA secondary structure reveals novel regulatory features. Nature 2014, 505, 696-700.

59. Mortimer, S.A.; Kidwell, M.A.; Doudna, J.A. Insights into RNA structure and function from genome-wide studies. Nat. Rev. Genet. 2014, 15, 469-479.

60. Rouskin, S.; Zubradt, M.; Washietl, S.; Kellis, M.; Weissman, J.S. Genome-wide probing of RNA structure reveals active unfolding of mRNA structures in vivo. Nature 2014, 505, 701-705.

61. Wan, Y.; Qu, K.; Zhang, Q.C.; Flynn, R.A.; Manor, O.; Ouyang, Z.; Zhang, J.; Spitale, R.C.; Snyder, M.P.; Segal, E.; et al. Landscape and variation of RNA secondary structure across the human transcriptome. Nature 2014, 505, 706-709.

62. Doudna, J.A.; Charpentier, E. Genome editing: The new frontier of genome engineering with CRISPR-Cas9. Science 2014, doi:10.1126/science. 1258096.

63. Cheng, C.J.; Bahal, R.; Babar, I.A.; Pincus, Z.; Barrera, F.; Liu, C.; Svoronos, A.; Braddock, D.T.; Glazer, P.M.; Engelman, D.M.; et al. MicroRNA silencing for cancer therapy targeted to the tumour microenvironment. Nature 2014, doi:10.1038/nature13905.

64. Meade, B.R.; Gogoi, K.; Hamil, A.S.; Palm-Apergi, C.; Berg, A.; Hagopian, J.C.; Springer, A.D.; Eguchi, A.; Kacsinta, A.D.; Dowdy, C.F.; et al. Efficient delivery of RNAi prodrugs containing reversible charge-neutralizing phosphotriester backbone modifications. Nat. Biotechnol. 2014, 32, $1256-1261$.

(C) 2015 by the authors; licensee MDPI, Basel, Switzerland. This article is an open access article distributed under the terms and conditions of the Creative Commons Attribution license (http://creativecommons.org/licenses/by/4.0/). 